\title{
Limonium sinuatum (L.) Mill. Yetiştiriciliğinde Farklı Yetiştirme Ortamlarının Bitki Besin Elementi İçeriklerine Etkisi
}

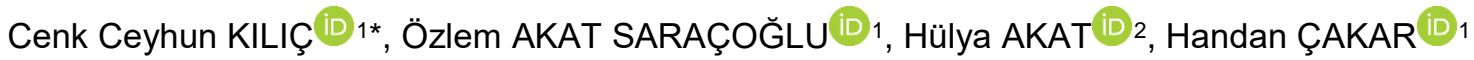 \\ ${ }^{1}$ Ege Üniversitesi, Bayındır Meslek Yüksekokulu, İzmir \\ ${ }^{2}$ Muğla Sıtkı Koçman Üniversitesi, Ortaca Meslek Yüksekokulu, Muğla \\ Geliş Tarihi (Received): 10.04.2020, Kabul Tarihi (Accepted): 03.05.2020 \\ $\square$ Sorumlu Yazar (Corresponding author ${ }^{*}$ ): cenk.kilic@ege.edu.tr \\ (C) +902325816317 且 +902325817330
}

öz

Araştırma, Limonium sinuatum (L.) Mill. yetiştiriciliğinde topraksız tarım ortam kültürü tekniği kullanımının verim ve bitki besin elementi içerikleri üzerindeki etkisini belirlemek amacıyla sera koşullarında yürütülmüştür. Bu amaçla torf, perlit, cüruf ve bunların eşit miktarlardaki karışımları (1:1:1) ile kontrol grubunu oluşturan toprak ortamı denemeye alınmıştır. Belirlenen amaca ulaşabilmek için verim ile bitkilerin yaprak ve kök aksamlarındaki bitki besin elementi analizleri gerçekleştirilmiştir. Bu çalışma, tesadüf parselleri deneme desenine uygun 3 tekrarlı olarak düzenlenmiştir. Her iki yılda da yetiştirme ortamlarının yapraktaki $\mathrm{P}, \mathrm{K}, \mathrm{Mg}, \mathrm{Fe}, \mathrm{Mn}$ ve $\mathrm{Cu}$ ile kökteki $\mathrm{P}, \mathrm{Ca}, \mathrm{Mg}, \mathrm{Fe}, \mathrm{Zn}$ ve Cu içerikleri üzerindeki etkileri istatistiki olarak önemli bulunmuştur $(\mathrm{p}<0.05)$. L. sinuatum (L.) Mill. bitkisinin, torf ve eşit miktarlardaki karışım ortamlarında (torf: perlit: cüruf) en iyi verimi gösterdiği ve gübreleme amacıyla kullanılan besin çözeltisinin yaprak ve kökteki bitki besin elementi içeriklerine göre bitki gelişimi için yeterli olduğu sonucuna ulaşılmıştır.

Anahtar Kelimeler: Deniz lavantası, topraksız tarım, gübreleme, verim

\section{Effect of Different Growing Media on Plant Nutrients in Limonium sinuatum (L.) Mill.}

\begin{abstract}
The objective of this study was to investigate the effect of the use of substrates culture in Limonium sinuatum (L.) Mill. growth on yield and plant nutrient contents in Greenhouse condition. For this purpose, peat, perlite, tuff and their mixtures in equal amounts $(1: 1: 1)$ and the soil as the control group were taken into the experiment. In order to achieve the specified goal, the yield was obtained and leaves and root nutrient content were analyzed. Experiment was laid out in randomized parcel design with three replications. In both years, the effects of growing medias on leaf $[P, K$, $\mathrm{Mg}, \mathrm{Fe}, \mathrm{Mn}$ and $\mathrm{Cu}]$ and root contents $[\mathrm{P}, \mathrm{Ca}, \mathrm{Mg}, \mathrm{Fe}, \mathrm{Zn}$ and $\mathrm{Cu}]$ were found statistically significant $(\mathrm{p}<0.05)$. It was concluded that Limonium sinuatum '(L.) Mill. showed the best yield in peat and equal amounts of mixture media (peat: perlite: tuff) and the nutrient solution used for fertilization was sufficient for plant development according to the plant nutrient content of the leaf and root.
\end{abstract}

Keywords: Statice, soilless culture, fertilization, yield 


\section{Giriş}

Ülkemizdeki bahçe bitkileri arasında ekonomik getirisi giderek artan ve insan psikolojisini iyileştirmenin yanı sıra daha sağlıklı nesillerin yetiştirilmesine de olanak tanıyan süs bitkilerine talep her geçen gün artmaktadır. Süs bitkilerinin özellikle çevre bilincinde meydana gelen olumlu değişim sonucu her alanda kullanımının yaygınlaşması, üretimin artmasına neden olarak süs bitkileri sektörünün gelişmesine olanak tanımıştır (Akat, 2019). Bu bağlamda son yıllarda artan ekonomik değerlerine bağıı olarak süs bitkileri konusunda yapılan çalışmaların her geçen gün önem kazandığı ve farklı alternatif türlerin kullanımıyla gerçekleştirilen yetiştiriciliğin sektöre çeşitlilik kattığı görülmektedir.

Plumbaginaceae (Dişotugiller) familyasına ait, alternatif kesme çiçek türlerinden biri olan Limonium sinuatum (L.) Mill. (Deniz Lavantası) bitkisi; değişik ekolojik koşullarda rahatıkla yetiştirilebilen, tuza dayanımı yüksek, peyzaj sahalarında kaya bahçesi ve bordür oluşturmak amacıyla mevsimlik süs bitkisi olarak kullanımlarının yanı sıra kesme çiçek ve kuru çiçek şeklinde de değerlendirilerek çok yönlü kullanıma uygun, farklı renk seçeneğine sahip, tek yıllık kullanımı yaygın olan ve ekonomik getirisi yüksek bir süs bitkisi türüdür (Hatipoğlu ve Gülgün, 1999; Yücel, 2002; Akat, 2012; Akat ve Özzambak, 2014). Bu türün, kesme çiçek olarak değerlendirilmesinde; bir bitkiden çok sayıda çiçek kesimine olanak tanımasının dışında ekonomik ve üretici bazında kolay bir şekilde yetiştirilebilmesi önemli avantaj oluşturmaktadır. Kesme çiçek olarak kullanımları, tek başına ana materyal şeklinde ya da çiçekli dolgu materyali olarak gerçekleştirilmektedir (Akat ve ark., 2017). Ayrıca bu türün vazo ömrünün oldukça uzun olması ve buket aranjmanlarında kontrast yaratmak amacıyla kullanılan hassas yapıdaki Gypsophilla paniculata türüne kıyasla dayanıklılığının dışında değişik renk seçenekleriyle alternatifler sunması da kesme çiçek sektörü açısından farklılıkların yaratılmasına olanak sağlamaktadır (Akat ve Özzambak, 2013). Kesme çiçekçilik sektöründe verimi artırmak ve tarımsal maliyetleri düşürmek amacıyla kimyasal gübre uygulamalarını azaltmak ekonomiye katkıda bulunmak adına en önemli konuların başında gelmektedir (Verlingen ve McDonald, 2007). Bu yönde yürütülen çalışmalar, besin maddelerinin dengeli oranlarda ve düzenli bir gübreleme programı ile uygulanmasının, $L$. sinuatum bitkisinin verim ve kalitesini önemli ölçüde yükselttiğini ortaya koymuştur (Papadapulos ve ark., 2006; Akat ve ark., 2012; Altunlu ve ark., 2013; Akat ve ark., 2014). Son yıllarda yetiştiricilikte bitki gelişimi, verim ve kaliteyi yükseltmek amacıyla yapılan bu uygulamaların yanı sıra alternatif yetiştiricilik sistemlerinin kullanımı da oldukça dikkat çekmektedir. Bunlardan biri olarak karşımıza çıkan topraksız yetiştiricilik; seradaki toprak kökenli sorun- ların çözümlenmesi amacıyla özellikle seracılığın gelişmiş olduğu ülkelerde yoğun olarak kullanılan bir yetiştiricilik şeklidir. Topraksız tarım tekniği, toprağın bulunmadığı veya tarımsal üretim için kalitesinin yeterli olmadığı durumlarda yetiştiriciliğin yapılabilmesine, toprak kökenli sorunların çözülmesinin yanı sıra su ve besin maddelerinin etkin bir şekilde kullanılarak erkenci, homojen, kaliteli ve yüksek verimin elde edilmesine, toprak işleme ve yabancı otlarla mücadeleyi gerektiren işlemleri ortadan kaldırarak otomasyonla birlikte iş gücünün en aza indirilebilmesi ile toprak ve yeraltı su kirliliğinin azaltılmasına veya engellenmesine olanak sağlamaktadır (Benoit ve Ceustermans, 1986; Winsor ve Schwarz, 1990; Abak ve ark., 1994; Gül 2008; Akat Saraçoğlu ve ark., 2017). Sera topraklarında yoğun üretim yapılması nedeniyle; toprak yorgunluğu, tuzluluk, drenaj yetersizliği, hastalık ve zararlı popülasyonunun artması gibi pek çok sorun ile karşılaşılmaktadır. Sayılan bu nedenlerden dolayı verim ve kalitesi azalan sera topraklarının iyileştirilmesi amacıyla üretim sezonu sonunda yıkanıp işlenmesi ile dezenfeksiyon işleminin gerçekleştirilmesinin fazla iş gücü gerektirmesinin yanı sıra maliyetleri arttırması, üretici düzeyinde uygulanabilirliğini zorlaştırmaktadır. Ayrıca geleneksel yetiştiricilikte karşılaşılan tüm olumsuzlukların önlenmesi dışında insan ve çevre sağlığı odaklı tarım tekniklerinin kullanması zorunluluğu da günümüz koşullarında göz ardı edilemez bir gerçek olarak karşımıza çıkmaktadır.

Yürütülen bu araştırmada; L. sinuatum (L.) Mill. yetiştiriciliğinin, toprağa alternatif farklı ortamlarda gerçekleştirilmesi ile ticari değeri olan alternatif türlerin devamlılığının sağlanmasının yanı sıra kesme çiçek sektörü içindeki payının arttırılmasına da önemli bir katkı sağlayacağı düşünülmektedir. Daha önce $L$. sinuatum (L.) Mill. ile ilgili yapılmış olan araştırmaların ışığında gerçekleştirilen bu çalışmada, bitkilerin farklı ortamlardaki reaksiyonunu ortaya koyabilmek adına verim ile bitki tarafından kaldıılan besin elementi içeriklerinin belirlenmesi hedeflenmiştir.

\section{MATERYAL VE YÖNTEM}

Araştırma, Ege Üniversitesi Bayındır Meslek Yüksekokulu'na ait PE örtülü ısıtmasız serada, 2012-2014 yılları arasında tesadüf parselleri deneme desenine uygun 3 tekerrürlü olacak şekilde gerçekleştirilmiştir. Limonium sinuatum (L.) Mill. bitkisel materyal olarak tercih edilerek balkon tipi yatay saksılara dikimler gerçekleştirilmiştir. Geleneksel yetiştiricilik şekli olarak kontrol uygulaması grubunu oluşturan bahçe toprağı $\left(\mathrm{O}_{1}\right)$ ile perlit $\left(\mathrm{O}_{2}\right)$, torf $\left(\mathrm{O}_{3}\right)$, cüruf $\left(\mathrm{O}_{4}\right)$ ve eşit hacimlerdeki perlit:torf:cüruf $(1: 1: 1)$ karışımından oluşan $\left(\mathrm{O}_{5}\right)$ yetiştirme ortamlarının bulunduğu topraksız tarım ortam kültürü kullanılarak yetiştiricilik açık besleme sistemi şeklinde gerçekleştirilmiştir. Denemeye alınan toprak ve yetiştirme ortamlarının 
bazı fiziksel ve kimyasal özellikleri Tablo 1 ve 2'de verilmiştir.

Tablo 1. Toprak materyaline ilişkin bazı fiziksel ve kimyasal analiz sonuçları

\begin{tabular}{|l|l|}
\hline Yapılan Analizler & Değerler \\
\hline Saturasyon & 35.33 (Tınlı) \\
$\mathrm{EC}(\mu \mathrm{S} / \mathrm{cm})$ & 298 \\
Tuz Toplam $(\%)$ & 0.006 (Tuzsuz) \\
$\mathrm{pH}$ & 7.05 (Nötr) \\
Organik Karbon & 1.11 \\
$\%$ Organik Madde & 1.92 \\
$\mathrm{CaCO}_{3}$ & 4.36 (Kireçli) \\
$\mathrm{P}_{2} \mathrm{O}_{5}(\mathrm{ppm})$ & 0.625 \\
$\mathrm{~K}_{2} \mathrm{O}(\mathrm{ppm})$ & 27.40 \\
\hline
\end{tabular}

Tablo 2. Yetiştirme ortamlarına ilişkin bazı fiziksel ve kimyasal özellikler

\begin{tabular}{|l|c|c|c|}
\hline \multirow{2}{*}{ Özellikler } & \multicolumn{3}{|c|}{ Değerler } \\
\cline { 2 - 4 } & Perlit & Torf & $\begin{array}{c}\text { Cü- } \\
\text { ruf }\end{array}$ \\
\hline pH & 6.8 & 5.8 & 7.92 \\
Toplam Tuz (\%) & - & 0.39 & 0.01 \\
Organik Madde (\%) & - & 46.73 & 0.19 \\
Su Tutma Kapasitesi (\%) & 289 & 330.15 & 43.27 \\
Porozite (\%) & 65.10 & 85 & 59.27 \\
\hline
\end{tabular}

Araştırmada bitkilerin su ve besin maddesi ihtiyacının karşılanması amacıyla; pH'sı yaklaşık 6.50-6.75 ve elektriksel iletkenliği ise $2.0-2.1 \mathrm{mS} / \mathrm{cm}$ civarında tutulan modifiye Hoagland besin reçetesinden yararlanılmıştır (Akat ve ark., 2015) (Tablo 3).

Tablo 3. Besin çözeltisinin kimyasal bileşimi ve kullanılan kaynaklar

\begin{tabular}{|c|c|c|}
\hline $\begin{array}{c}\text { Besin } \\
\text { Elementi }\end{array}$ & $\begin{array}{c}\text { Kullanılan Miktar } \\
(\mathrm{ppm})\end{array}$ & Kullanılan Kimyasal Kaynak ve Bileşimi \\
\hline $\mathrm{N}$ & 120 & $\mathrm{NH}_{4} \mathrm{NO}_{3}(\% 33 \mathrm{~N})$ \\
\hline $\mathrm{P}$ & 80 & $\operatorname{MAP}\left(\% 61 \mathrm{P}_{2} \mathrm{O}_{5}, \% 12 \mathrm{~N}\right)$ \\
\hline $\mathrm{K}$ & 180 & $\mathrm{~K}_{2} \mathrm{SO}_{4}\left(\% 51 \mathrm{~K}_{2} \mathrm{O}\right)$ \\
\hline $\mathrm{Ca}$ & 200 & 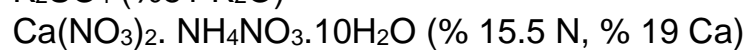 \\
\hline $\mathrm{Mg}$ & 50 & $\mathrm{MgSO}_{4} .7 \mathrm{H}_{2} \mathrm{O}(\% 16 \mathrm{MgO})$ \\
\hline $\mathrm{Fe}$ & 3 & $\mathrm{Na}_{2} \mathrm{Fe}-\mathrm{EDTA}(\% 1.5 \mathrm{Fe})$ \\
\hline $\mathrm{Zn}$ & 0.5 & $\mathrm{ZnSO}_{4} .7 \mathrm{H}_{2} \mathrm{O}(\% 19-20 \mathrm{Zn})$ \\
\hline $\mathrm{Mn}$ & 0.5 & $\mathrm{MnSO}_{4} . \mathrm{H}_{2} \mathrm{O}(\% 23-28 \mathrm{Mn})$ \\
\hline $\mathrm{B}$ & 0.5 & $\mathrm{H}_{3} \mathrm{BO}_{3}(\% 17 \mathrm{~B})$ \\
\hline $\mathrm{Cu}$ & 0.02 & $\mathrm{CuSO}_{4} .5 \mathrm{H}_{2} \mathrm{O}(\% 20 \mathrm{Cu})$ \\
\hline Mo & 0.05 & $\left(\mathrm{NH}_{4}\right)_{6} \mathrm{Mo}_{7} \mathrm{O}_{24 .} 4 \mathrm{H}_{2} \mathrm{O}(\% 54 \mathrm{Mo})$ \\
\hline
\end{tabular}

Besin çözeltisinin bitkilere dağıtılması ve uygulanmasında, iklim parametreleri esas alınarak saksı drenaj çıkışlarında yapılan gözlemler sonucu miktarlar belirlenip 2 adet $1 \mathrm{~m}^{3^{\prime}}$ lük tank ile $16 \mathrm{~mm}$ dış çapa sahip PE lateral boruya bağlanan $8.4 \mathrm{l} / \mathrm{h}$ debili basınç düzenleyici damlatıcıların yer aldığı damla sulama sisteminden faydalanılmıştır (Şekil 1).
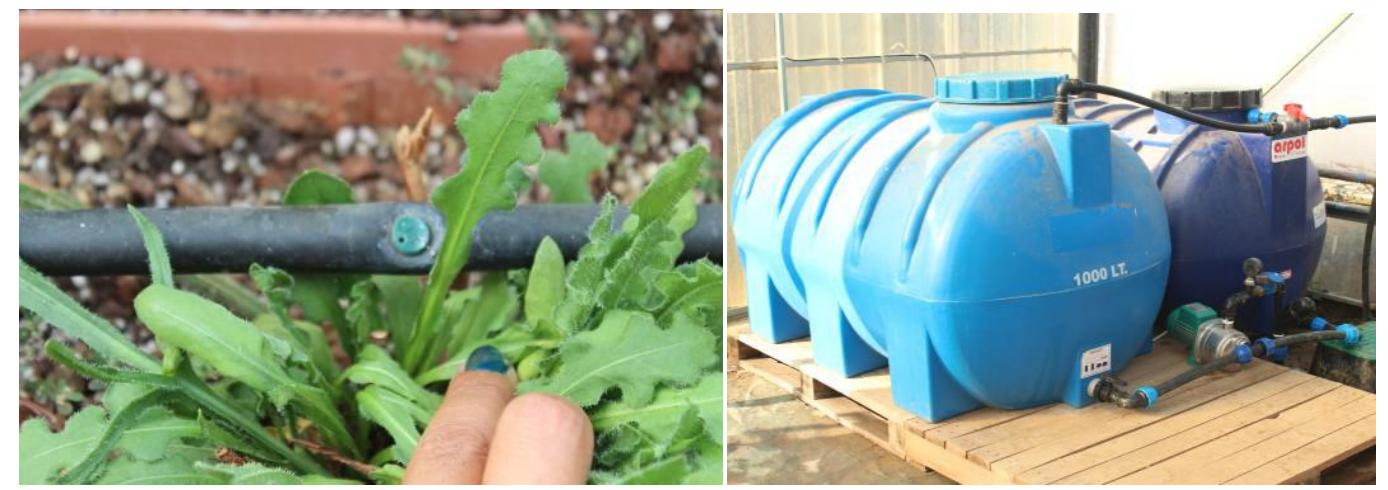

Şekil 1. Damlatıcı - lateral boru hattı ve besin çözeltisi tanklarına ilişkin görünüm 
Bitkilerin 11 adet $/ \mathrm{m}^{2}$ olacak şekilde (Mellesse ve ark., 2013) deneme saksılarına dikimlerinden, besin çözeltisi uygulanana kadarki geçirdiği süreçte tüm konulara eşit miktarda sulama yapılmıştır. Bitkiler homojen görünüm ve büyüklüğe ulaştığında bitki besin elementleri sulama suyu ile uygulanmıştır. Araştırmaya ilişkin takvim Tablo 4 'de verilmiştir.

Tablo 4. Denemeye ait üretim takvimi

\begin{tabular}{|l|c|c|}
\hline İşlemler & I. Yıl & II. Y.l \\
\hline Dikim ve & $05.12 .2012-$ & $28.11 .2013-$ \\
Söküm & 01.07 .2013 & 01.07 .2014 \\
\hline İlk ve Son & $08.04 .2013-$ & $21.04 .2014-$ \\
Hasat & 28.06 .2013 & 27.06 .2014 \\
\hline Gübreleme & $14.01 .2013-$ & $30.12 .2013-$ \\
Başlangıcı & 29.06 .2013 & 28.06 .2014 \\
\hline
\end{tabular}

Deneme sonunda bitkilerden alınan yaprak ve kök örnekleri laboratuvarda ön temizlik işlemleri yapıldıktan sonra $65^{\circ} \mathrm{C}$ 'de kurutulmuş, kuruyan örnekler öğütülerek analize hazır hale getirilmiştir (Chapman and Pratt,1961).

Yaprak ve bitki örneklerinden 1'er gram tartılarak yaş yakma yöntemi $\left(4 \mathrm{kısım} \mathrm{HNO}_{3}+1 \mathrm{kısım} \mathrm{HClO}_{4}\right)$ ile yakılıp hazırlanmıştır. Örneklerin yaş yakılması ile elde edilen sıvı örneklerde $\mathrm{K}, \mathrm{Na}, \mathrm{Ca}, \mathrm{Mg}, \mathrm{Fe}, \mathrm{Cu}, \mathrm{Mn}, \mathrm{Zn}$ Shimadzu AA-6200 Atomik Absorpsiyon Spektrofotometresin (AAS)'de okunmuştur. $P$ vanadomolibdofosforik sarı renk yöntemi ile Optima SP-3000 Plus Spektrofotometresinde belirlenmiştir (Lott, 1956; Kacar, 1972; Kacar ve Kovancı, 1982).
Elde edilen tüm veriler; TARIST istatistiksel analiz paket programında varyans analizi uygulanarak LSD testi ile istatistiksel analizleri gerçekleştirilmiştir (Açıkgöz ve ark., 2004).

\section{ARAŞTIRMA BULGULARI VE TARTIŞMA}

\section{Verime İlişkin Bulgular}

I. yıl hasat; üretim 08.04.2013'de başlayıp, 28.06.2013 tarihinde sonlanarak toplam 12, II. yılda ise 21.04.2014'de başlayıp, 26.06.2014 tarihinde sonlanarak 10 hasat yapılımıştır. Araştırma konusu olarak ele alınan farklı yetiştirme ortamlarının verim üzerindeki etkilerine ilişkin istatistiksel analiz sonuçları her iki üretim dönemi için ayrı değerlendirilmeye alınarak Şekil 2'de verilmiştir. Buna göre birim alandan elde edilen verimler birbirine yakın rakamsal değerler göstermekle birlikte, ortamlar arasında farklılıklar sergilemiştir. I. yılda en yüksek verimi 373 adet $/ \mathrm{m}^{2}$ ile $\mathrm{O}_{3}$ ortamından alınırken, II. yılda $427 \mathrm{adet} / \mathrm{m}^{2}$ ile $\mathrm{O}_{5}$ ortamından alınmıştır. Ortamlara iliş̧in en düşük verimler ise I. ve II. yıllar için sırasıyla, $267 \mathrm{adet} / \mathrm{m}^{2}$ ile $\mathrm{O}_{1}$ ve $331 \mathrm{adet} / \mathrm{m}^{2}$ ile $\mathrm{O}_{4}$ ortamlarından alınmıştır. Ortamlardan elde edilen verimler; II. yılda, I. yıla kıyasla $\mathrm{O}_{1}$ ortamı için $\% 21.9, \mathrm{O}_{2}$ ortamı için $\% 12.1, \mathrm{O}_{3}$ ortamı için \% 5.4, $\mathrm{O}_{4}$ ortamı için \% 14.5 ve $\mathrm{O}_{5}$ ortamı için $\% 25.0$ daha yüksek bulunmuştur. İki üretim dönemi arasındaki bu farklılığın fide temin edilen firmanın II. yılda göndermiş oldukları fidelerde; verimini arttırmak amacıyla yaptıkları vernalizasyon (soğuk uygulaması) uygulamasından kaynaklandığı kanısına varılmıştır.

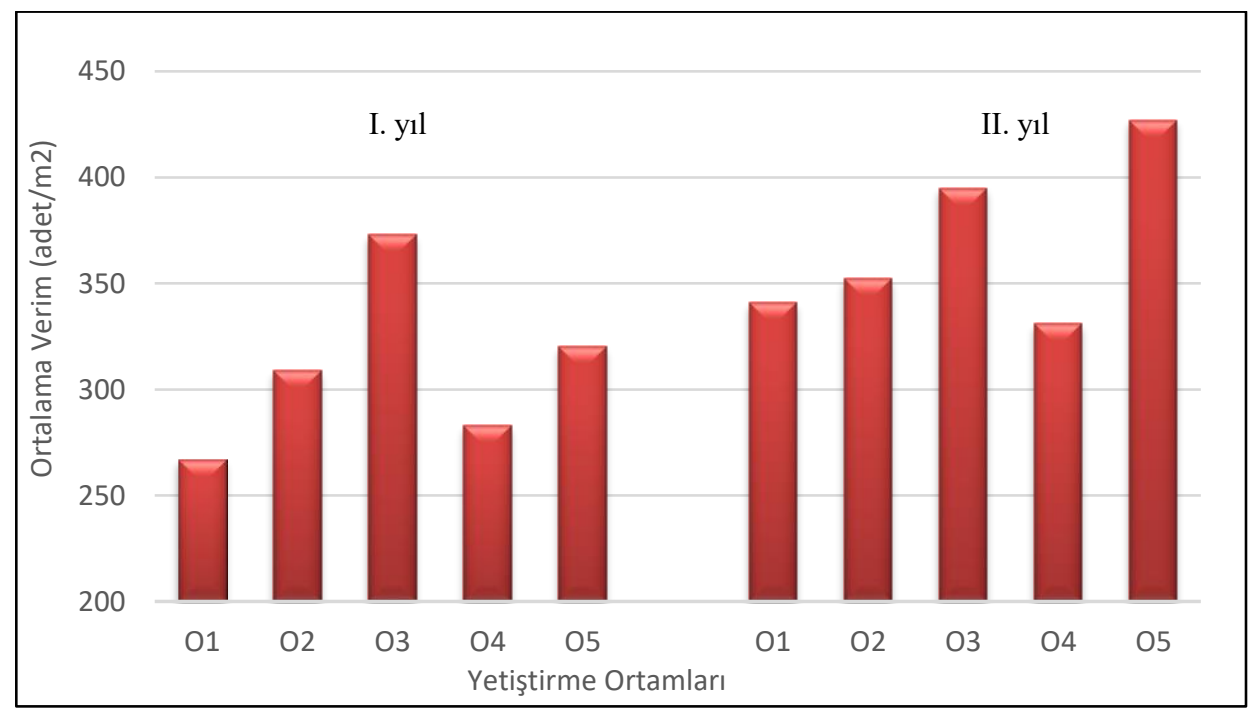

Şekil 2. Yetiştirme ortamlarının verime etkisi (adet $\mathrm{m}^{-2}$ ) 


\section{Bitki besin elementi içerikleri}

\section{Fosfor (P)}

L. sinuatum 'Compindi White' kültivarı için denemeye alınan uygulama konularının yapraktaki bitki besin maddeleri üzerindeki etkisini veren istatistiksel değerlendirmenin yapıldığı Tablo 5 ve 6 incelendiğinde; her iki üretim döneminde yetiştirme ortamlarının ortalama $\mathrm{P}, \mathrm{K}, \mathrm{Ca}$, $\mathrm{Mg}, \mathrm{Na}, \mathrm{Fe}, \mathrm{Cu}, \mathrm{Mn}$ ve $\mathrm{Zn}$ elementleri üzerinde yarattığı istatistiksel etki benzer olmuştur. Buna göre, ana faktör ortam altında her iki yılda yetiştirme ortamlarının P üzerindeki etkisi $p<0.05$ düzeyinde önemli bulunmuştur. I. yıl için en yüksek $\mathrm{P}$ değeri $\% 0.47$ ile $\mathrm{O}_{3}$ ortamında ve en düşük $\mathrm{P}$ ise $\% 0.32$ ile $\mathrm{O}_{5}$ ortamında tespit edilmiştir. II. yılda da en yüksek $\mathrm{P}$ içeriği $\% 0.43$ ile $\mathrm{O}_{3}$ ortamından alınırken, en düşük $P$ içeriği $\% 0.29$ ve $\% 0.21$ ile aynı istatistiksel grup içerisinde yer alan sırasıyla $\mathrm{O}_{4}$ ve $\mathrm{O}_{5}$ ortamlarından alınmıştır. Genel olarak değerlendirildiğinde; her iki yıl için yaprak $P$ içerikleri birbirine yakın düzeylerde olduğu belirlenmiştir. L. sinuatum Compindi White' kültivarı için denemeye alınan uygulama konularının köklerindeki bitki besin maddeleri üzerindeki etkisini veren istatistiksel değerlendirmenin yapıldığı Tablo 8 ve 9 incelendiğinde; her iki üretim döneminde yetiştirme ortamlarının ortalama $\mathrm{P}, \mathrm{K}, \mathrm{Ca}, \mathrm{Mg}, \mathrm{Na}, \mathrm{Fe}, \mathrm{Cu}$, $M n$ ve $\mathrm{Zn}$ elementleri üzerinde yarattığı istatistiksel etki benzer olmuştur. Buna göre, iki yılda da yetiştirme ortamlarının $P$ üzerindeki etkisi $p<0.05$ düzeyinde önemli bulunmuştur. I. yıl için en yüksek $P$ değeri $\% 0.50$ ile $\mathrm{O}_{4}$ ortamında ve en düşük $\mathrm{P}$ ise $\% 0.42$ ile $\mathrm{O}_{3}$ ortamında tespit edilmiştir. II. yılda en yüksek $\mathrm{P}$ içeriği $\% 0.46$ ile $\mathrm{O}_{5}$ ortamından alınırken, en düşük $\mathrm{P}$ içeriği $\% 0.17 \mathrm{O}_{3}$ ortamından alınmıştır. L. sinuatum yaprak ve köklerindeki $P$ değerleri birbirine yakın ve Jones et al. (1991)'a göre yeterli kabul edilen \%0.30-0.70 arasında yer aldığı bulunmuştur (Tablo 7). Araştırmada elde edilen verilerin birçok araştırmacının sonuçları ile benzer olduğu belirlenmiştir (Fascella ve Zizzo, 2004; Akat ve ark., 2017; Akat ve ark., 2012; Akat ve ark., 2013; Akat ve ark., 2015a; Hanan ve ark., 2016; Akat Saraçoğlu ve ark., 2017; Kottayam ve ark., 2014).

\section{Potasyum (K)}

Tablo 5 ve 6'da verilen yaprak $\mathrm{K}$ değerleri incelendiğinde; ana faktör ortam altında her iki yılda yetiştirme ortamlarının $\mathrm{K}$ üzerindeki etkisi $p<0.01$ düzeyinde önemli bulunmuştur. Her iki üretim döneminde de en yüksek K içeriği I. yılda \%6.34 ile II. yılda \%5.96 ile O ${ }_{1}$ ortamından elde edilmiştir. En düşük $\mathrm{K}$ içeriği ise, I. yılda \%4.07 ile $\mathrm{O}_{2}$ ve II. yılda ise \%3.65 ile $\mathrm{O}_{5}$ ortamında elde edilmiştir. Kökteki K değerleri incelendiğinde, iki yılda da yetiştirme ortamlarının $\mathrm{K}$ üzerindeki etkisi istatistiki olarak önemsiz bulunmuştur. I. yıl için en yüksek $\mathrm{K}$ içeriği \% 0.59 ile $\mathrm{O}_{1}$ ortamında ve en düşük $\mathrm{K}$ ise $\% 0.36$ ile $\mathrm{O}_{5}$ ortamında tespit edilmiştir. II. yılda ise en yüksek $\mathrm{K}$ içeriği $\% 1.13$ ile $\mathrm{O}_{5}$ ortamında, en düşük K içeriği \%0.19 $\mathrm{O}_{4}$ ortamından alınmıştır (Tablo 8 ve 9). L. sinuatum'un yapraklarındaki $\mathrm{K}$ değeri Jones ve ark. (1991)'a göre yeterli kabul edilen \%3.00-5.00 arasında yer almıştır (Tablo 7). Köklerdeki K değerlerine bakıldığında ise iki yıldaki yaprak $\mathrm{K}$ değerlerinden daha az miktarlarda olduğu tespit edilmiştir. Elde edilen veriler birçok araştırmacının sonuçları ile benzer bulunmuştur (Akat ve ark., 2012; Akat ve ark., 2015b; Hanan ve ark., 2016).

\section{Kalsiyum (Ca)}

Yetiştirme ortamlarının Ca üzerindeki etkisi istatistiki açıdan önemsiz bulunmuştur. I. yıl için en yüksek Ca değeri $\% 1.17$ ile $\mathrm{O}_{5}$ ortamında ve en düşük $\mathrm{Ca}$ ise $\% 0.55$ ile $\mathrm{O}_{1}$ ve 0.56 ile $\mathrm{O}_{4}$ ortamlarında tespit edilmiştir. II. yılda ise en yüksek $\mathrm{Ca}$ değeri \% 2.86 ile $\mathrm{O}_{3}$ ortamında, en düşük $\mathrm{Ca}$ içeriği \%1.59 ile $\mathrm{O}_{5}$ ortamında bulunmuştur. Sonuç olarak, her iki üretim döneminde de yaprak Ca içerikleri birbirine yakın düzeylerde olduğu belirlenmiştir (Tablo 5 ve 6). Kök Ca değerleri incelendiğinde, iki yıl için yetiştirme ortamlarının Ca üzerindeki etkisi $p<0.01$ düzeyinde istatistiki açıdan önemli bulunmuştur. I. yılda en yüksek $\mathrm{Ca}$ değeri \%1.17 ile $\mathrm{O}_{2}$ ortamında ve en düşük $\mathrm{Ca}$ ise $\% 0.21$ ile $\mathrm{O}_{5}$ ortamında tespit edilmiştir. II. yılda ise en yüksek $\mathrm{Ca}$ değeri $\% 2.65$ ile $\mathrm{O}_{2}$ ortamında, en düşük $\mathrm{Ca}$ içeriği \%1.95 $\mathrm{O}_{5}$ ortamından alınmıştır (Tablo 8 ve 9). $L$. sinuatum'un yaprak ve köklerindeki $\mathrm{Ca}$ değerleri birbirine yakın çıkarak Jones ve ark. (1991)'a göre yeterli kabul edilen \%0.5-1.00 değerleri arasında yer almıştır (Tablo 7). Elde edilen sonuçların birçok araştırmacı tarafından ulaşılan sonuçlarla benzer olduğu belirlenmiştir (Akat ve ark., 2012; Akat ve Özzambak, 2013; Akat ve Özzambak, 2014; Altunlu ve ark., 2013; Akat ve ark., 2013b; Akat ve ark., 2015a; Hanan ve ark., 2016).

\section{Magnezyum (Mg)}

L. sinuatum yaprak $\mathrm{Mg}$ değerleri incelendiğinde; iki yılda da yetiştirme ortamlarının $\mathrm{Mg}$ üzerindeki etkisi $p<0.05$ düzeyinde istatistiki açıdan önemli bulunmuştur. I. yıl için en yüksek $\mathrm{Mg}$ değeri \%1.85 ile $\mathrm{O}_{5}$ ortamında ve en düşük $\mathrm{Mg}$ ise $\% 1.71$ ile $\mathrm{O}_{4}$ ortamında bulunmuştur. II. yılda ise tüm ortamlar aynı gruba girmekle birlikte en yüksek $\mathrm{Mg}$ değeri \%1.62 ile $\mathrm{O}_{3}$ ortamında, en düşük $\mathrm{Mg}$ içeriği \%1.58 $\mathrm{O}_{1}$ ortamından alınmıştır (Tablo 5 ve 6). Köklerdeki Mg değerleri incelendiğinde; iki yılda da yetiştirme ortamlarının $\mathrm{Mg}$ üzerindeki etkisi $\mathrm{p}<0.1$ düzeyinde istatistiki açıdan önemli bulunmuştur I. yıl için en yüksek $\mathrm{Mg}$ değeri 1.14 ile $\mathrm{O}_{2}$ ortamında ve en düşük $\mathrm{Mg}$ ise $\% 0.54$ ile $\mathrm{O}_{5}$ ortamında tespit edilmiştir. II. yılda ise en yüksek $\mathrm{Mg}$ değeri \%1.62 ile $\mathrm{O}_{3}$ ortamında, en düşük $\mathrm{Mg}$ içeriği $\% 1.58$ ile $\mathrm{O}_{1}$ ortamında alınmıştır. Ayrıca II. yılda istatistiki olarak yetiştirme ortamları aynı gruba girmiştir (Tablo 
8 ve 9). L. sinuatum'un yapraklarındaki Mg değeri, Jones ve ark. (1991)'a göre \%1.20 değerinin üzerinde saptanarak yüksek olduğu belirlenirken, köklerdeki Mg değeri 0.50-1.20 değerleri arasında bulunarak yeterli olduğu tespit edilmiştir (Tablo 7). Yaprak ve kökte ilişkin elde edilen bu sonuçlar birçok araştırmacının sonuçları ile benzerlik göstermektedir (Akat ve ark., 2012; Akat ve ark., 2015a; Hanan ve ark., 2016).

\section{Sodyum (Na)}

Tablo 5 ve 6 'da verilen yaprak Na değerleri incelendiğinde; iki yılda da yetiştirme ortamlarının $\mathrm{Na}$ üzerindeki etkisi istatistiki açıdan önemsiz bulunmuştur. Her iki üretim döneminde de en yüksek Na içeriği hem I. yılda 407 $\mathrm{mgkg}^{-1}$ ile hem de II. yılda $429 \mathrm{mgkg}^{-1}$ ile $\mathrm{O}_{5}$ ortamından elde edilmiştir. En düşük Na içeriği ise, I. yılda $360 \mathrm{mgkg}$ 1 ile $\mathrm{O}_{1}$ ve II. yılda ise $395 \mathrm{mgkg}^{-1}$ ile $\mathrm{O}_{3}$ ortamında elde edilmiştir. Kök Na değerleri incelendiğinde; iki yılda da yetiştirme ortamlarının $\mathrm{Na}$ üzerindeki etkisi istatistiki açıdan önemsiz bulunmuştur. I. yılda en yüksek $\mathrm{Na}$ içeriği $431 \mathrm{mgkg}^{-1}$ ile $\mathrm{O}_{3}$, II. yılda ise $429 \mathrm{mgkg}^{-1}$ ile $\mathrm{O}_{5}$ ortamından elde edilmiştir. En düşük $\mathrm{Na}$ içeriği ise, I. yılda 356 $\mathrm{mgkg}^{-1}$ ile $\mathrm{O}_{5}$ ve II. yılda ise $300 \mathrm{mgkg}^{-1}$ ile $\mathrm{O}_{1}$ ortamında elde edilmiştir (Tablo 8 ve 9).

\section{Demir (Fe)}

Tablo 5 ve 6 'da verilen yaprak Fe değerleri incelendiğinde, iki yılda da yetiştirme ortamlarının yaprak Fe üzerindeki etkisi $p<0.01$ düzeyinde istatistiki açıdan önemli bulunmuştur. I. yıl için en yüksek Fe değeri $219 \mathrm{mgkg}^{-1}$ ile $\mathrm{O}_{3}$ ortamında ve en düşük $\mathrm{Fe}$ ise $57 \mathrm{mgkg}^{-1}$ ile $\mathrm{O}_{1}$ ortamında tespit edilmiştir. II. yılda ise en yüksek Fe değeri $93 \mathrm{mgkg}^{-1}$ ile $\mathrm{O}_{1}$ ortamında ve en düşük Fe içeriği $69 \mathrm{mgkg}^{-1}$ ile $\mathrm{O}_{2}$ ortamından alınmıştır. Kök Fe değerleri incelendiğinde, iki yılda yetiştirme ortamlarının Fe üzerindeki etkisi $p<0.01$ düzeyinde istatistiki açıdan önemli bulunmuştur. I. yıl için en yüksek Fe değeri $141.48 \mathrm{mgkg}$ ${ }_{1}^{1}$ ile $\mathrm{O}_{3}$ ortamında ve en düşük $\mathrm{Fe}$ ise $65.40 \mathrm{mgkg}^{-1}$ ile $\mathrm{O}_{4}$ ortamında tespit edilmiştir. II. yılda ise en yüksek Fe değeri $113.73 \mathrm{mgkg}^{-1}$ ile $\mathrm{O}_{4}$ ortamında, en düşük $\mathrm{Fe}$ içeriği $49.08 \mathrm{mgkg}^{-1}$ ile $\mathrm{O}_{2}$ ortamından alınmıştır. Genel olarak değerlendirildiğinde; her iki üretim döneminde de kök $\mathrm{Fe}$ içerikleri birbirine yakın düzeylerde olduğu belirlenmiştir (Tablo 8 ve 9). L. sinuatum'un yapraklarındaki Fe değeri Jones et al. (1991)'a göre yeterli kabul edilen 50$200 \mathrm{mgkg}^{-1}$ arasında yer alırken, köklerindeki Fe içeriği de yaprak değerlerine yakın düzeyde bulunmuştur (Tablo 7). Yaprak ve kök sonuçları diğer araştırmacıların sonuçları ile paralellik göstermiştir (Akat ve ark., 2012; Akat ve ark. 2013; Akat ve ark., 2015a; Hanan ve ark., 2016).

Tablo 5. I. yılda yetiştirme ortamlarının yapraktaki bitki besin elementi içeriklerine etkisi

\begin{tabular}{|c|c|c|c|c|c|c|c|c|c|c|}
\hline \multirow{3}{*}{\multicolumn{2}{|c|}{ Yetiştirme Ortamları }} & \multicolumn{9}{|c|}{ I. yıl } \\
\hline & & \multicolumn{4}{|c|}{$\%$} & \multicolumn{5}{|c|}{$\mathrm{mgkg}^{-1}$} \\
\hline & & $\mathbf{P}$ & $\mathbf{K}$ & $\mathrm{Ca}$ & Mg & $\mathrm{Na}$ & $\mathrm{Fe}$ & $\mathrm{Zn}$ & Mn & $\mathrm{Cu}$ \\
\hline \multicolumn{2}{|c|}{ Bahçe Toprağı (Kontrol) $\left(\mathbf{O}_{1}\right)$} & $0.45 a$ & $6.34 a$ & 0.55 & $1.77 \mathrm{bc}$ & 360 & $57 \mathrm{c}$ & 116 & $104 a$ & 9.5 \\
\hline Perlit & $\left(\mathrm{O}_{2}\right)$ & $0.35 b$ & $4.07 b$ & 0.68 & $1.83 a b$ & 401 & $126 b$ & 190 & $103 a$ & 13.2 \\
\hline Torf & $\left(\mathrm{O}_{3}\right)$ & $0.47 a$ & $5.85 a$ & 0.61 & $1.78 b$ & 389 & $219 a$ & 212 & $136 a$ & 23.1 \\
\hline Curuf & $\left(\mathrm{O}_{4}\right)$ & $0.35 b$ & $5.85 a$ & 0.56 & $1.71 \mathrm{c}$ & 382 & $93 b$ & 148 & $98 a b$ & 13.5 \\
\hline Karışım & $\left(\mathrm{O}_{5}\right)$ & $0.32 b$ & $4.56 b$ & 1.17 & $1.85 a$ & 407 & $81 b$ & 174 & $43 b$ & 21.4 \\
\hline Ortam L & & $0.077^{*}$ & $1.266^{\star \star}$ & Öd & $0.067^{\star}$ & Öd & $42^{\star \star}$ & Öd & $39.24^{\star \star}$ & $12.83^{*}$ \\
\hline
\end{tabular}

Ö.d = önemsiz ; ${ }^{*}=$ Önemli \%5 alfa seviyesinde ; ${ }^{* *}=$ Önemli \%1 alfa seviyesinde 
Limonium sinuatum (L.) Mill. Yetiştiriciliğinde Farklı Yetiştirme Ortamlarının Bitki Besin Elementi İçeriklerine Etkisi

Tablo 6. II. yılda yetiştirme ortamlarının yapraktaki bitki besin elementi içeriklerine etkisi

\begin{tabular}{|c|c|c|c|c|c|c|c|c|c|c|}
\hline \multirow{3}{*}{\multicolumn{2}{|c|}{ Yetiştirme Ortamları }} & \multicolumn{9}{|c|}{ II. yıl } \\
\hline & & \multicolumn{4}{|c|}{$\%$} & \multicolumn{5}{|c|}{$\mathrm{mgkg}^{-1}$} \\
\hline & & $\mathbf{P}$ & $\mathbf{K}$ & $\mathrm{Ca}$ & Mg & $\mathrm{Na}$ & $\mathrm{Fe}$ & $\mathrm{Zn}$ & Mn & $\mathrm{Cu}$ \\
\hline \multicolumn{2}{|c|}{ Bahçe Toprağı (Kontrol) $\left(\mathbf{O}_{1}\right)$} & $0.39 a$ & $5.96 \mathrm{a}$ & 2.59 & $1.58 \mathrm{a}$ & 400 & $93 a$ & 336 & $115 a$ & 22.6 \\
\hline Perlit & $\left(\mathrm{O}_{2}\right)$ & $0.41 a$ & $5.48 \mathrm{ab}$ & 1.61 & $1.61 \mathrm{a}$ & 397 & $69 b$ & 280 & $119 a$ & 12.1 \\
\hline Torf & $\left.\mathrm{O}_{3}\right)$ & $0.43 a$ & $5.84 a b$ & 2.86 & $1.62 a$ & 395 & $81 a$ & 171 & $32 c$ & 23.0 \\
\hline Curuf & $\left.\mathrm{O}_{4}\right)$ & $0.29 b$ & $4.62 \mathrm{bc}$ & 1.81 & $1.59 a$ & 412 & $75 a$ & 223 & $71 \mathrm{bc}$ & 16.8 \\
\hline Karışım & $\left(\mathrm{O}_{5}\right)$ & $0.21 b$ & $3.65 c$ & 1.59 & $1.60 \mathrm{a}$ & 429 & $82.1 \mathrm{a}$ & 155 & $93 a b$ & 13.4 \\
\hline Ortam L & & $0.077^{\star}$ & $1.266^{\star \star}$ & Öd & $0.067^{\star}$ & Öd & $42^{\star \star}$ & Öd & $39.24^{\star \star}$ & 12.83 \\
\hline
\end{tabular}

Ö.d = önemsiz ; ${ }^{*}=$ Önemli \%5 alfa seviyesinde ; ${ }^{* *}=$ Önemli \%1 alfa seviyesinde

Tablo 7. L. sinuatum yaprak kritik değerleri

\begin{tabular}{|c|c|c|c|}
\hline Bitki Besin Elementi & Düşük & Yeterli & Yüksek \\
\hline$N(\%)$ & $3.00-3.49$ & $3.50-6.00$ & $>6.0$ \\
\hline$P(\%)$ & $0.25-0.29$ & $0.3-0.7$ & $>0.7$ \\
\hline $\mathrm{K}(\%)$ & $2.50-2.99$ & $3.0-5.0$ & $>5.0$ \\
\hline $\mathrm{Ca}(\%)$ & $0.30-0.49$ & $0.5-1.0$ & $>1.0$ \\
\hline $\mathrm{Mg}(\%)$ & $0.30-0.49$ & $0.5-1.20$ & $>1.2$ \\
\hline$B\left(\mathrm{mgkg}^{-1}\right)$ & $16-19$ & $20-40$ & $>40$ \\
\hline $\mathrm{Cu}\left(\mathrm{mgkg}^{-1}\right)$ & $5-6$ & $7-25$ & $>25$ \\
\hline $\mathrm{Fe}\left(\mathrm{mgkg}^{-1}\right)$ & $40-49$ & $50-200$ & $>200$ \\
\hline $\operatorname{Mn}\left(\mathrm{mgkg}^{-1}\right)$ & $40-49$ & $50-200$ & $>200$ \\
\hline $\mathrm{Zn}\left(\mathrm{mgkg}^{-1}\right)$ & $20-24$ & $25-200$ & $>200$ \\
\hline
\end{tabular}

Tablo 8. I. yılda yetiştirme ortamlarının kökteki bitki besin elementi içeriklerine etkisi

\begin{tabular}{|c|c|c|c|c|c|c|c|c|c|c|}
\hline \multirow{3}{*}{\multicolumn{2}{|c|}{ Yetiştirme Ortamları }} & \multicolumn{9}{|c|}{ I. YII } \\
\hline & & \multicolumn{4}{|c|}{$\%$} & \multicolumn{5}{|c|}{ mgkg $^{-1}$} \\
\hline & & $\mathbf{P}$ & $\mathrm{K}$ & $\mathrm{Ca}$ & Mg & $\mathrm{Na}$ & $\mathrm{Fe}$ & $\mathrm{Zn}$ & Mn & $\mathrm{Cu}$ \\
\hline \multicolumn{2}{|c|}{ Bahçe Toprağı (Kontrol) $\left(0_{1}\right)$} & $0.49 a$ & 0.59 & $0.96 \mathrm{a}$ & $1.07 \mathrm{a}$ & 384 & $67 \mathrm{~b}$ & $23 \mathrm{~b}$ & 80 & $4.49 a$ \\
\hline Perlit & $\left(\mathrm{O}_{2}\right)$ & $0.46 \mathrm{a}$ & 0.55 & $1.17 \mathrm{a}$ & $1.14 \mathrm{a}$ & 363 & $98 \mathrm{~b}$ & $33 a$ & 66 & $7.83 a$ \\
\hline Torf & $\left(\mathrm{O}_{3}\right)$ & $0.42 b$ & 0.58 & $0.66 \mathrm{ab}$ & $0.73 b$ & 431 & $141 \mathrm{a}$ & 10d & 40 & $3.88 \mathrm{a}$ \\
\hline Curuf & $\left(\mathrm{O}_{4}\right)$ & $0.50 \mathrm{a}$ & 0.46 & $0.92 a$ & $0.69 \mathrm{~b}$ & 387 & $65 b$ & $28 a b$ & 12 & $2.99 a$ \\
\hline Karışım & $\left(\mathrm{O}_{5}\right)$ & $0.45 a$ & 0.36 & $0.21 \mathrm{~b}$ & $0.54 \mathrm{~b}$ & 356 & 68.b & $15 c$ & 16 & $5.04 a$ \\
\hline \multicolumn{2}{|c|}{ DönemxOrtam LSD 0.05} & $0.100^{\star *}$ & Öd & $0.66^{\star \star}$ & $0.217^{\star *}$ & Öd & $40.11^{*}$ & $7.69^{\star *}$ & Öd & 7.11* \\
\hline
\end{tabular}

Ö.d = önemsiz ; * = Önemli \%5 alfa seviyesinde ; ** = Önemli \%1 alfa seviyesinde 
Tablo 9. II. yılda yetiştirme ortamlarının kökteki bitki besin elementi içeriklerine etkisi

\begin{tabular}{|c|c|c|c|c|c|c|c|c|c|c|}
\hline \multirow{3}{*}{\multicolumn{2}{|c|}{ Yetiştirme Ortamları }} & \multicolumn{9}{|c|}{ II. YII } \\
\hline & & \multicolumn{4}{|c|}{$\%$} & \multicolumn{5}{|c|}{$\mathrm{mgkg}^{-1}$} \\
\hline & & $\mathbf{P}$ & K & $\mathrm{Ca}$ & Mg & $\mathrm{Na}$ & $\mathrm{Fe}$ & Zn & Mn & $\mathrm{Cu}$ \\
\hline \multicolumn{2}{|c|}{ Bahçe Toprağı (Kontrol) $\left(\mathbf{O}_{1}\right)$} & $0.37 a$ & 0.93 & $2.46 a b$ & $1.58 \mathrm{a}$ & 346 & $98 a$ & $39 a$ & 83 & $19.67 a$ \\
\hline Perlit & $\left(\mathrm{O}_{2}\right)$ & $0.37 a$ & 0.99 & $2.65 a$ & $1.61 \mathrm{a}$ & 359 & $49 b$ & $29 b$ & 67 & 16.99ab \\
\hline Torf & $\left(\mathrm{O}_{3}\right)$ & $0.17 b$ & 1.10 & $2.56 a$ & $1.62 a$ & 300 & $96 a$ & $17 \mathrm{c}$ & 70 & 16.92ab \\
\hline Curuf & $\left(\mathrm{O}_{4}\right)$ & $0.42 a$ & 0.19 & $2.33 a b$ & $1.59 \mathrm{a}$ & 380 & $113 a$ & $38 a$ & 103 & $11.77 \mathrm{~b}$ \\
\hline Karışım & $\left(\mathrm{O}_{5}\right)$ & $0.46 a$ & 1.13 & $1.95 b$ & $1.60 \mathrm{a}$ & 429 & $96 a$ & $33 a b$ & 76 & $3.65 c$ \\
\hline \multicolumn{2}{|c|}{ DönemxOrtam LSD 0.05} & $0.100^{\star *}$ & Öd & $0.66^{\star *}$ & $0.217^{\star \star}$ & Öd & $40.11^{*}$ & $7.69^{\star *}$ & Öd & $7.11^{\star}$ \\
\hline
\end{tabular}

Ö.d = önemsiz ; ${ }^{*}=$ Önemli \%5 alfa seviyesinde ; ${ }^{* *}=$ Önemli \%1 alfa seviyesinde

\section{Çinko (Zn)}

Íki yılda da yetiştirme ortamlarının yaprak $\mathrm{Zn}$ içerikleri üzerindeki etkisi istatistiki açıdan önemsiz bulunmuştur. I. yıl için en yüksek $\mathrm{Zn}$ değeri $212 \mathrm{mgkg}^{-1}$ ile $\mathrm{O}_{2}$ ortamında ve en düşük $\mathrm{Zn}$ ise $116 \mathrm{mgkg}^{-1}$ ile $\mathrm{O}_{1}$ ortamında tespit edilmiştir. II. yılda ise en yüksek $\mathrm{Zn}$ değeri 336 $\mathrm{mgkg}^{-1}$ ile $\mathrm{O}_{1}$ ortamında, en düşük $\mathrm{Zn}$ içeriği $155 \mathrm{mgkg}^{-1}$ ile $\mathrm{O}_{5}$ ortamından alınmıştır (Tablo 5 ve 6). Köklerdeki $Z n$ değerleri incelendiğinde, iki yılda da yetiştirme ortamlarının Zn üzerindeki etkisi $p<0.01$ düzeyinde istatistiki açıdan önemli bulunmuştur. I. yıl için en yüksek $\mathrm{Zn}$ değeri $33 \mathrm{mgkg}^{-1}$ ile $\mathrm{O}_{2}$ ortamında ve en düşük $\mathrm{Zn}$ ise 10 $\mathrm{mgkg}^{-1}$ ile $\mathrm{O}_{3}$ ortamında tespit edilmiştir. II. yılda ise en yüksek $\mathrm{Zn}$ değeri $39 \mathrm{mgkg}^{-1}$ ile $\mathrm{O}_{1}$ ortamında, en düşük $\mathrm{Zn}$ içeriği $17 \mathrm{mgkg}^{-1}$ ile $\mathrm{O}_{3}$ ortamından alınmıştır. Genel olarak değerlendirildiğinde; her iki üretim döneminde de kök Zn içerikleri birbirine yakın düzeylerde olduğu belirlenmiştir (Tablo 8 ve 9). L. sinuatum'un yapraklarındaki Zn değeri Jones et al., (1991)'a göre yeterli kabul edilen. 25-200 $\mathrm{mgkg}^{-1}$ arasında yer alırken, köklerdeki Zn değerinin yapraklara oranla daha düşük değerlerde olduğu saptanmıştır (Tablo 7). Sonuçların birçok araştırmacının sonuçları ile paralellik gösterdiği belirlenmiştir (Fascella ve Zizzo, 2004; Akat ve ark., 2012; Akat ve ark., 2013; Kottayam ve ark., 2014; Akat ve ark., 2015; Hanan ve ark., 2016; Akat Saraçoğlu, 2017;; Akat ve ark., 2020).

\section{Mangan (Mn)}

Tablo 5 ve 6'da verilen yaprak değerleri incelendiğinde, iki yılda da yetiştirme ortamlarının Mn üzerindeki etkisi $p<0.01$ düzeyinde istatistiki açıdan önemli bulunmuştur. I. yıl için en yüksek $\mathrm{Mn}$ değeri $136 \mathrm{mgkg}^{-1}$ ile $\mathrm{O}_{3}$ ortamında ve en düşük $\mathrm{Mn}$ ise $43 \mathrm{mgkg}^{-1}$ ile $\mathrm{O}_{5}$ ortamında tespit edilmiştir. II. yılda ise en yüksek Mn değeri 119 $\mathrm{mgkg}^{-1}$ ile $\mathrm{O}_{2}$ ortamında, en düşük $\mathrm{Mn}$ içeriği $32 \mathrm{mgkg}^{-1}$ ile $\mathrm{O}_{3}$ ortamından alınmıştır. Genel olarak değerlendirildiğinde; her iki üretim döneminde de yaprak Mn içerikleri birbirine yakın düzeylerde olduğu belirlenmiştir. Köklerdeki Mn değerleri incelendiğinde; iki yılda da yetiştirme ortamlarının Mn üzerindeki etkisi istatistiki açıdan önemsiz bulunmuştur. I. yıl için en yüksek $\mathrm{Mn}$ değeri $80 \mathrm{mgkg}$ ${ }_{1}^{1}$ ile $\mathrm{O}_{1}$ ortamında ve en düşük $\mathrm{Mn}$ ise $12 \mathrm{mgkg}^{-1}$ ile $\mathrm{O}_{4}$ ortamında tespit edilmiştir. II. yılda ise en yüksek Mn değeri $103 \mathrm{mgkg}^{-1}$ ile $\mathrm{O}_{4}$ ortamında, en düşük Mn içeriği 67 $\mathrm{mgkg}^{-1}$ ile $\mathrm{O}_{2}$ ortamından alınmıştır. Genel olarak değerlendirildiğinde; her iki üretim döneminde de kök Mn içerikleri birbirine yakın düzeylerde olduğu belirlenmiştir (Tablo 8 ve 9). L. sinuatum'un yapraklarındaki Mn değeri Jones ve ark. (1991)'a göre yeterli kabul edilen 50-200 $\mathrm{mgkg}^{-1}$ arasında saptanarak köklerdeki Mn değerleri bu sonuçlara yakın bulunmuştur (Tablo 7). Yaprak ve kök sonuçlarının birçok araştırmacının sonuçları ile benzer olduğu belirlenmiştir (Akat ve ark., 2012; Akat ve ark., 2015a; Hanan ve ark., 2016).

\section{Bakır (Cu)}

İki yılda da yetiştirme ortamlarının $\mathrm{Cu}$ üzerindeki etkisi istatistiki açıdan önemsiz bulunmuştur ( $p>0.05)$. I. yıl için en yüksek $\mathrm{Cu}$ değeri $23.1 \mathrm{mgkg}^{-1}$ ile $\mathrm{O}_{3}$ ortamında ve en düşük $\mathrm{Cu}$ ise $9.5 \mathrm{mgkg}^{-1}$ ile $\mathrm{O}_{1}$ ortamında elde edilmiştir. II. yılda ise en yüksek Cu değeri $23.0 \mathrm{mgkg}^{-1}$ ile $\mathrm{O}_{3}$ ortamında, en düşük $\mathrm{Cu}$ içeriği $12.1 \mathrm{mgkg}^{-1} \mathrm{O}_{2}$ ortamından alınmıştır. Genel olarak değerlendirildiğinde; her iki üretim döneminde de yaprak $\mathrm{Cu}$ içerikleri birbirine yakın düzeylerde olduğu belirlenmiştir (Tablo 5 ve 6). Tablo 8 ve 9'da köklerdeki Cu değerlerine bakıldığında; iki yılda da yetiştirme ortamlarının $\mathrm{Cu}$ üzerindeki etkisi $p<0.05$ düzeyinde istatistiki açıdan önemli bulunmuştur. I. yıl için en yüksek Cu değeri $7.83 \mathrm{mgkg}^{-1}$ ile $\mathrm{O}_{2}$ ortamında ve en düşük $\mathrm{Cu}$ ise $2.99 \mathrm{mgkg}^{-1}$ ile $\mathrm{O}_{4}$ ortamında elde edilmiştir. II. yılda ise en yüksek Cu değeri $19.67 \mathrm{mgkg}^{-1}$ ile $\mathrm{O}_{1}$ ortamında, en düşük Cu içeriği $3.65 \mathrm{mgkg}^{-1} \mathrm{O}_{4}$ ortamından alınmıştır. Genel olarak değerlendirildiğinde; ikinci üretim döneminde de kök $\mathrm{Cu}$ içerikleri I. Döneme göre 
daha yüksek düzeyde olduğu belirlenmiştir. $L$. sinuatum'un yaprak ve köklerindeki Cu değerleri birbirine yakın çıkarak Jones ve ark. (1991)'a göre yüksek kabul edilen 7-25 mgkg-1 değerleri arasında bulunmuştur (Tablo 7). Elde edilen sonuçlar birçok araştırmacının sonuçları ile benzerlik göstermiştir (Akat ve ark., 2012; Akat ve ark., 2015a; Hanan ve ark., 2016).

\section{SONUÇ}

Kesme çiçekçilik sektöründe alternatif türler arasında ticari anlamda yerini alan $L$. sinuatum bitkisine ilişkin yapılan çalışmaların az olması nedeni ile bu tür ile ilgili olarak literatür bazında henüz tam olarak belirlenmemiş ve çözüme ulaştırılması gereken konuların başında kalite parametreleri ile gübreleme dikkat çekmektedir. Ancak, araştırmamızda bitki gelişiminde etkin rol oynayan bitki besin elementlerinin yaprak ve kök tarafından kaldırılan miktarlarının ortaya konulması bakımından ulaşılan sonuçlar geleneksel (toprak) ve topraksız yetiştiricilik ortamlarındaki bitki besleme çalışmaları alanında büyük önem taşımaktadır. Her iki yılda da yetiştirme ortamlarının yapraktaki $\mathrm{P}\left(0.077^{\star}\right), \mathrm{K}\left(1.266^{* \star}\right), \mathrm{Mg}\left(0.067^{*}\right)$, Fe $\left(42^{\star \star}\right)$, Mn $\left(39.24^{\star \star}\right), \mathrm{Cu}\left(12.83^{*}\right)$ ve kökteki $\mathrm{P}\left(0.100^{\star}\right)$, $\mathrm{Ca}\left(0.66^{* *}\right), \mathrm{Mg}\left(0.217^{* *}\right), \mathrm{Fe}\left(40.11^{\star}\right), \mathrm{Zn}\left(7.690^{* *}\right)$, Cu $\left(7.11^{*}\right)$ içerikleri üzerindeki etkileri istatistiki olarak önemli bulunmuştur.

Sonuç olarak $L$. sinuatum bitkisinin, torf ve eşit miktarlardaki karışım ortamlarında (torf: perlit: cüruf) en iyi verimi gösterdiği ve gübreleme amacıyla kullanılan modifiye Hoagland besin çözeltisinin yaprak ve kökteki bitki besin elementi analizleri doğrultusunda bitki gelişimi için yeterli olduğu sonucuna ulaşılmıştır. Farklı ortamlarda yetiştirilen $L$. sinuatum bitkisinin gelişim süreci sonrasında bitkinin (yaprak ve kök) yetiştirme ortamından kaldırdığı bitki besin maddeleri yapılan analizlerle belirlenerek sonraki çalışmalara da ışık tutacak şekilde ortaya konulmuştur. Tüm bu analizler, çalışmalar ve değerlendirmeler; halofit karakteri ile sorunlu alanlarda da üretim olanağı sağlayan $L$. sinuatum bitkisinde en yüksek verime ulaşılması amacıyla gerçekleştirilmiş olup araştırma sonuçlarının bu konuda çalışan üreticilere de bir rehber ve yol gösterici olması arzu edilmektedir.

\section{TEŞEKKÜR}

2012/BAMYO/002 nolu BAP kapsamında yürütülen bu çalışmaya katkılarından dolayı Ege Üniversitesi Bilimsel Araştırma Projeleri Koordinatörlüğüne teşekkür ederiz.

\section{KAYNAKLAR}

Abak, K., Sevgican, A., Çolakoğlu, H., Eryüce., N., Gül, A., Baytorun, N., Çelikel, G., Paksoy,M. (1994). Sera Tarımında Topraksız Yetiştirme Üzerinde Araştırmalar. TÜBíTAK-TOAG 884 No'lu Araştırma Projesi Sonuç Raporu. 84 s.

Açıkgöz N., İlker, E., Gökçöl, A. (2004). Bilgisayarda biyolojik araştırmalarının değerlendirilmesi. EU TOTEM Yayın No:2, Izmir.

Akat, H., Çolak Esetlili,B., Altunlu, H., Köşkeroğlu, S., Yokas, I. and Kılınç, R. (2010). Effect of potassium doses on plant nutrition and quality of Statice (Limonium sinuatum). "Soil Management and Potash Fertilizer Uses in West Asia and North Africa Region" International Symposium, s: 161-166. 22-25 November 2010, Antalya-Turkey.

Akat, H. (2012). Tuz Stresi Koşullarında Yetiştirilen Limonium sinuatum (Statice) Bitkisinde Kalsiyum Uygulamalarının Verim ve Gelişim Üzerine Etkisi, E.Ü. Fen Bilimleri Enstitüsü, E.Ü. Fen Bil. Enst. Doktora Tezi, $158 \mathrm{~s}$.

Akat H., Altunlu, H., Çolak Esetlili, B., Yokaş, İ., Kılınç,R. (2012). Effects of different amounts of nitrogen and potassium nutrition on nutrient content, plant growth and quality of Limonium sinuatum. Volume V, Nutrient management for soil sustainability, food security and human health, (Ed: Dilek Anaç, M. Tolga Esetlili, H. Hüsnü Kayikçioğlu). 8th International Soil Science Congress on "Land Degradation and Challenges in Sustainable Soil Management" May 1517, 2012 Çeşme-İzmir, TURKEY. Proceedings book. Takım Numarası: 978-975-96629-6-7 ISBN:978-60563090-1-4 (5.c) 169-174s. http://www.soilcongress.ege.edu.tr.

Akat, H., Özzambak, M.E. (2013). The effects of Ca application on some stress parameters of Limonium sinuatum under salinity conditions in the greenhouse growing. Journal of Tekirdag Agricultural Faculty, Cilt:10, Sayı:1, Sayfa. 48-58.

Akat H., Altunlu, H., Çolak Esetlili, B., Akat Saraçoğlu, Ö., Yokaş, İ. (2013a). The effect of phosphorus doses on nutrient content, growth, yield and quality properties of Limonium sinuatum. The $11^{\text {th }}$ Dahlia Greidinger Memorial Symposium. Organized and supporter by: The Dahlia Greidinger Memorial Fund and BARD The United StatesIsrael Bi-national Agricultural Research and Development Fund 4-7 March, 2013 Technion-IIT

Akat, H., Altunlu, H., Akat, Ö., Çetinkale Demirkan, G., Özzambak,M.E and Yokas, İ. (2013b). Effect of calcium in mitigating adverse effects of salt on yield and different physiological attributes of Statice (Limonium sinuatum) under open field condition. $1^{\text {st }}$ Central Asia Congress on Modern Agricultural Tecniques and Plant Nutrient, 01-03 October 2013, Bishkek-Krygyzstan. Soil- Water Journal, Volume 2 (1): 3542. ISSN: 2146-7072.

Akat, H., Altunlu, H., Çolak Esetlili, B., Akat, Ö., Çetinkale Demirkan G., Yokas, İ. (2013c). Farklı demir dozlarının bitkisinde gelişim, verim ve kalite üzerine etkisi. Uludağ Üniv. Ziraat Fak. Derg., 27(2): 13-18. ISBN: 1301-3165.

Akat, H., Özzambak, M.E. (2014). The Effects of Ca application on some stress parameters under salinity conditions in the open field growing of Limonium sinuatum. Ege Üniv. Ziraat Fak. Derg., 51(1): 59-68, ISSN: 1008-8851. DOI: 10.20289/zfdergi.423273. 
Akat, H., Çetinkale Demirkan, G., Akat Saraçoğlu, Ö., Yağmur B., Yokaş, İ. (2015a). Arıtma çamuru uygulamalarının Limonium sinuatum 'compindi white' çeşidinde bitki gelişimi, verim ve çiçek kalitesi üzerine etkileri. Ege Üniv. Ziraat Fak. Derg. 52 (1):107-114 ISSN 1018 - 8851.

Akat, H., Çetinkale Demirkan, G., Akat Ö., Yokaş, İ. (2015b). 'Limonium sinuatum' yetiştiriciliğinde farklı ortamlara ilave edilen atık su arıtma çamurunun süs bitkisi yetiştirme materyali karışımı olarak kullanımı. Tekirdağ Ziraat Fak. Derg., Journal of Tekirdağ Agriculture Faculty, 12(1): 8190, ISSN: 1302-750.

Akat Saraçoğlu, Ö., Akat,H., Güneş, A., Çakar H., Kılıç, C.C. (2017). Limonium sinuatum 'Compindi White' ve 'Compindi Deep Blue' çeşitlerinde farklı yetiştirme ortamlarının gelişim ve verim üzerine etkileri. Ege Üniv. Ziraat Fak. Derg., 54(2): 187-195, ISSN: 1018-8851. DOI: 10.20289/zfdergi.423273.

Akat, H., Şahin, O., Çetinkale Demirkan G., Akat Saraçoğlu, Ö. (2017). Süs bitkisi üretim teknikleri, Efil Yayınevi, (Ed: Yokaş, İ.), ISBN: 978-605-4160-66-2, Ankara, s:135.

Akat, H., (2019). Muğla ili süs bitkileri sektörünün mevcut durumu ve değerlendirilmesi. International Turkic World Congress on Science and Engineering, s: 1438-1447. 17-18 June 2019, Niğde-Turkey. ISBN:978-975-8062-32-4.

Altunlu, H., Akat, H., Akat, O., Özzambak M.E., Yokas, İ. (2013). Effects of calcium application on yield and some physiological attributes of statice (limonium sinuatum) grown under salinity conditions. $1^{\text {st }}$ Central Asia Congress on Modern Agricultural Techniques and Plant Nutrient, 01 03 October 2013, Bishkek-Krygyzstan. Soil Water Journal, Volume 2 (1): 43-50. ISSN: 2146-7072.

Benoit, F., Ceustermans, N. (1986). Growth control of tomatoes and cucumbers NFT by means of rockwool and polyurethane blocks. Soilless Culture 2(2):3-9.

Chapmann, H. D., and Pratt, P.F. (1961). Methods of Analysis for Soils, Plant and Waters. University of California, Division of Agricultural Sciences.

Fascella,G. Zizzo Istituto, G.V. (2004). Influence of greenhouse roof opening system on internal climate and Limonium yield control. Proc. VII IS on Prot. Cult. Mild Winter Climates Eds. D.J. Cantliffe, P.J. Stoffella \& N. Shaw Acta Hort. 659, ISHS.
Gül, A., (2008). Topraksız Tarım. Hasad Yayıncılık, ISBN:978975- 8377-66-4, $144 \mathrm{~s}$.

Hanan E. Ibrahim., Hanan El-Fadaly, G.H., Assem A. M. ElNaggar, (2016). Study on the response of statice plants ( $\mathrm{Li}-$ monium sinuatum, I.) to humic acid application Alexandria Science Exchange Journal, vol. 37, No.3

Hatipoğlu, A., Gülgün, B. (1999). Tek ve Çok Yıllık Mevsimlik Çiçekler, Kent Matbaası, İzmir, 208s.

Jones, Jr., Benton, J., Benjamin Wolf, Harry A. Mills, (1991). Plant Analysis Handbook: A Practical Sampling, Preparation, Analysis, and Interpretation Guide Hardcover. ISBN 1 878148-001. Printed in the U.S.A. 151p

Kacar, B., Kovancı, İ. (1982). Bitki, Toprak ve Gübrelerde Kimyasal Fosfor Analizleri ve Sonuçlarının Değerlendirilmesi. Ege Üniv. Ziraat Fak. Yayınları No: 354.

Kacar, B., (1972). Bitki ve Toprak Kimyasal Analizleri. II. Bitki Analizleri, Ankara Üniv. Ziraat Fak. Yayın No: 453.

Kottayam, S., Sartaj A., Ansari, H. (2014). Yield quality of statice [Limonium sinuatum (L.) Mill.] as affected by cultivars and planting densities. Int. Journal of Horticulture and Floriculture Vol. 2 (6), pp. 89-97.

Lott, W.L. (1956). Leaf Analysis Technique in Coffee Research. IBEC. Research Inst. Publish.

Mellese, B., Kassa N., Mohammed, A. (2013). Yield and quality of statice [Limonium sinuatum (L.) Mill.] as affected by cultivars and planting densities. African Journal of Plant Science., 7(11): 528- 537.

Papadapulos, I., Chimonidou, D., Savvides., S., Polycarpou, P. (2006). Optimization of irrigation with treated wastewater on flower cultivation. Proceeding of ICID Conference 7-11 December 2004, Cario-Egypt 53:227-235.

Verlingen S., Mc Donald, I. (2007). Productivity and quality of statice (Limonium sinuatum cv. Soirre Mix) and cockscomb (Celosia argentea cv. Chief Mix) under organic and inorganic fertilization regiments. Scientia Horticulturae, 114(3): 199-206.

Winsor, G.W., Schwarz. M. (1990). Soilless Culture for Horticultural Crop Production. FAO Plant Production and Protection Paper, No: 101, Rome, pages 188.

Yücel, E. (2002). Türkiye 'de Yetişen Çiçekler ve Yer Örtücüler, Etam Yayınevi, ISBN 975-93746-1-7, Eskişehir. 